ledge have made such a text overdue; and in their chapters (pp. 15-205) on the origin and migration of orebearing fluids, on physical and chemical controls of ore deposition, on wall-rock alteration and gangue, on paragenesis and zoning, and on geothermometry, Profs. Park and MacDiarmid convey to the senior undergraduate who will use this work a judicious appreciation of the investigations of the past two decades. The remainder of the book (pp. 207-456), concerned with the classification of ore deposits and the description of well-chosen typical ore-fields, closely follows the system of Lindgren "which represents a fundamental standard by which most United States geologists attempt to classify ore deposits". Perhaps the main demerit of this system, as presented here, is over-insistence on the assumption that hydrothermal fluids "arose directly from an underlying magmatic source", a hypothesis which seems of doubtful validity in connexion with the great stratiform deposits which now furnish a very large part of the metal production of the world. Recognition that igneous intrusions and orogenic activity can stimulate the circulation at depth of intra. stratal brines and other groundwaters, which in turn can derive metals from the rocks which they traverse, seems in many cases to provide a channel between the Scylla of plutonism and the Charybdis of neptunism, on one or other of which hazards, according to the personal predilections of the professional reader, some of the authors' conclusions may be held to founder.

In their introduction, the authors emphasize that "the study of ore deposits and of ore genesis is not an exact science". On the mode of genesis of nearly all the great ore-types of the world-such as gold-uranium bankets, copper shales and red-bed coppers, noritic nickel ores, jaspilite iron deposits, and titanium ore-bodies in anorthosites - there are two antagonistic schools of thought; and in description of these debatable mineralizations an attempt has been made to give both sides of the issues, to a degree which may frustrate the mediocre student who likes cut-and-dried explanations but which will inspire the good student to think for himself. A. few factual errors common in foreign text-books have been perpetuated. Thus the statement (p. 388) that the alum shale of Sweden carries as much as 0.5 per cent uranium is analogous to saying that chalk carries as much as 99 per cent silica-this high tenor of uranium occurring in the diagenetic nodules of kolm is altogether different from the alum shale, much as flint is different from chalk. Again, the observation (p. 454) that "platinum is found as well-defined nuggets in the Witwatersrand" is scarcely in keeping with the facts that the principal platinoid present is osmiridium, that it rarely if ever exceeds 0.1 $\mathrm{mm}$ in grain size, and that the tenor in the Witwatersrand ores (only four times the clarke) is comparable to that in many gold-uranium veins of undoubted hydrothermal parentage. But these criticisms are very minor ones. In a text for undergraduates one would have welcomed a little about non-metallic ores-minerals such as diamond, magnesite, asbestos, and most other non-metallics are not dealt with. Despite this, however, the book fills a present need. It will be warmly welcomed and will deservedly have a wide circulation. C. F. DAvIDSON

\section{CORRELATION BY FOSSILS}

Time in Stratigraphy

By Dr. Alan B. Shaw. (International Series in the Earth Sciences.) Pp. xiv + 365. (New York: McGraw-Hill Book Company, Inc.; Maidenhead: McGraw-Hill Publishing Company, Ltd., 1964.) 10.50 dollars; $81 s .6 d$.

$7 \mathrm{TH}$ valuable part of Time in Stratigraphy consists of the exposition and illustration of a new method for improving stratigraphic correlation by fossils. By applying his method to certain strata in Texas, Dr. A. B. Shaw demonstrates that it is possible to subdivide the succession much more finely than by the present method of zoning. As a consequence, different sections may be much more accurately correlated with one another than has hitherto been possible. Should trial establish the validity of the method, its application to a variety of successions could lead to a breakthrough in various evolutionary and sedimentation investigations.

The method involves the determination of a standard succession of ranges of fossils, measured in units of length through a particular suitably chosen reference-section. The ranges are those not only of fossils occurring in that section, and extended where evidence from other sections shows an earlier entry or a later disappearance, but including also points of entry and disappearance of other species interpolated from other sections. The procedure used in interpolation from other sections into the standard is the essence of the method. In comparing another section with the standard, two processes are involved: (a) the differing thicknesses of strata corresponding to equal intervals of time and arising out of the different rates of accumulation of the two sections must be allowed for; (b) the two successions must be correlated. Both processes are carried out at the same time by a statistical method which can take account of all the different range limits common to both sections. In practice, not all range limits are used in the calculation, as some can be shown to be more valuable than others in particular cases.

By the successive incorporation into the standard of data from a series of sections, the quality of the standard is continuously improved. When all available suitable sections have been used, it is possible to go back over the sections and compare them successively with the improved standard which is thereby continuously further improved. The revision can be carried on along these lines until no further improvement results.

The statistical procedure used in interpolating data from other sections into the standard can now be applied for the comparison of any other section with the perfected. standard. Thus the best possible correlation can be obtained.

It can be seen that this method of correlation is superior to present methods, in that it makes use of far more data and because it is much less arbitrary and subjective. The statistical technique is simple and the calculations can be made readily on an ordinary desk calculating machine.

On theoretical grounds, the method may be criticized for its assumption that rates of sedimentation are reasonably uniform throughout a given section. It would not be difficult to investigate this assumption by dividing up various sections and testing the variation in rate of accumulation in each part. Indeed, this ought always to be done before correlations are attempted if there are marked changes of lithology or other grounds for suspecting lack of uniformity during deposition.

The price of the book is obviously a consequence of the large number of complicated tables. These are absolutely necessary in the main, though there is some avoidable repetition and the columns of standard equivalent levels in Tables $A-4$ and $A-6$ are unexplained and confusing. It would seem that an attempt has been made to make the price more palatable by throwing in something extra, namely the first seventy-one pages of the book, which are concerned with general principles of stratigraphy. On the basis of this first part of the book, it has been given the rather meaningless title Time in Stratigraphy which suggests that the book is a contribution to general stratigraphy. Unfortunately there is insufficient reference to actual examples to make the discussion of principles worth while, especially where these principles are either new or formulated in a new way. In any event, all this is unnecessary, as the later part of the book does not depend on any new principles or new application of old principles. The book is only of real value for its new method of correlation, and it is not to be recommended to general students of stratigraphy. S. Simpson 